\title{
A Study on Prevalence of Colour Vision Defects and Correlation with Sex, Visual Acuity and Blood Groups of the Study Group
}

\author{
Ila Venkata Padma ${ }^{1}$, Sanghamitra Panda ${ }^{2}$ \\ ${ }^{1}$ Assistant Professor Physiology Shadan Institute of Medical Sciences Hyderabad India, ${ }^{2}$ Professor HOD \\ Department of Physiology Shadan Institute of Medical Sciences Hyderabad India
}

\begin{abstract}
Inherited color blindness is a lifelong challenge. While it may limit prospects for certain jobs, most people find ways to adapt to the condition. Colour vision defect is usually for red-green colour and it is X-linked recessive trait. It is mainly homozygous that develop colour vision defects. Female heterozygous usually have normal vision. Colour vision defects also have a strong genetic component, especially if both parents have colour vision defects, and people with a particular blood group, and very myopic or hypermetropic , there is a good chance their child will be same. Color blindness is often apparent at a young age when children are learning their colours and goes undetected because as they grow they learn to associate specific colours with certain objects.For example, they come to know that grass is green, so they call the colour they see green. If symptoms are very mild, a person may not realize that they don't see certain colours.
\end{abstract}

Key Words: Partial colour blindness, Mutations in OPN1LW, OPN1MW,Deuteranopia , Protanopia, Photopigment of Retina.

\section{Introduction}

John Dalton described his own color blindness in 1794. In common with his brother, he confused scarlet with green and pink with blue. Dalton supposed that his vitreous humor was tinted blue, selectively absorbing longer wavelengths. He instructed that his eyes should be examined after his death, but the examination revealed that the humors were perfectly clear. Experiments on DNA extracted from his preserved eye tissue showed that Dalton was a deuteranope, lacking the middlewave photopigment of the retina. This diagnosis is shown to be compatible with the historical record of his phenotype, although it contradicts Thomas Young's belief that Dalton was a protanope $\mathrm{e}^{[1]}$.

Seeing colors is subjective. It is impossible to know how people with colour vision defects (CVD) see reds, greens, and other colors the same way as people with perfect vision. It is important for children to be tested before they start school because many early childhood educational materials involve identifying colors. However, there's no cure for inherited color blindness. When detected eye specialist may prescribe tinted glasses or contact lenses that can assist in distinguishing colors.

Processing of visual information under photopic conditions is initiated by three types of photoreceptor $\mathrm{S}$, $\mathrm{M}$, and Lsensitive cone and subsequently mediated by a luminance and two opponent chromatic mechanisms, the red/green (or L/M) and yellow/blue (or $[\mathrm{L}+\mathrm{M}] / \mathrm{S}$ ) channels. Each cone type is sensitive to a broad range of wavelengths, but has its own peak sensitivity (e.g., 440, 543, and $566 \mathrm{~nm}$ for the S, M, and L-cones, respectively

2]. Signals of the M- and L-cones are additively fed into the luminance channel and compared in the $\mathrm{L} / \mathrm{M}$ chromatic opponent channel. The $(\mathrm{L}+\mathrm{M}) / \mathrm{S}$ chromatic opponent channel compares the responses from the S-cone and the summed responses from the L- and M-cones ${ }^{[3]}$.

Colour vision is mediated by three types of cones and two chromatic opponent mechanisms. Absence or alteration of any cone type causes color vision deficiency (CVD) and lead to dichromatic or anomalous trichromatic color vision ${ }^{[4,5.6 .7]}$. The most common CVD is $\mathrm{X}$-chromosome-linked red-green colour blindness which 
occurs mostly in males ${ }^{[8]}$ and has two subtypes: protan and deutan. The protan subtype is further subdivided into protanopia, characterized by missing L-cones, and protanomaly, characterized by defective L-cones with a shift in peak sensitivity toward that of M-cones. The deutan subtype can be subdivided into deuteranopia, characterized by missing M-cones, and deuteranomaly, characterized by defective M-cones with a shift in peak sensitivity toward that of L-cones ${ }^{[8]}$. The luminance response for protan subjects is dominated by normal M-cones, whereas L-cones dominate the response for deutan subjects. Thus, relative to normal colour vision (CN), with which luminance sensitivity is determined by a combination of both normal L- and M-cones, protan subjects are more sensitive to shorter wavelengths, whereas deutan subjects are more sensitive to longer wavelengths. If luminance sensitivity and cone contrast are important factors controlling emmetropization and myopia development, as suggested by Rucker and Kruger $^{[9]}$, refraction measurements for eyes with CVD and eyes with $\mathrm{CN}$ should be different.

Objectives: To study the prevalence of colour vision defects in students joining our medical college.

\section{Materials \& Methods}

The presence of CVD is determined using the Ishihara pseudoisochromatic plates, and repeating the test for the second time to avoid false positives. Tests were performed binocularly with spectacle correction under artificial daylight illumination. It is appreciated that this technique is of practical value in investigating colour vision defects. All 1000 students were also tested for errors of refraction. 96 students were myopic and are wearing glasses and they are instructed to read Ishihara charts without removing glasses. The refractive status of all 1000 students is tested by using Snellen charts.Blood group testing is done for all the participants by glass slide method using anti-A,anti-B antisera. As a diagnostic procedure, Ishihara / pseudoisochromatic charts are of advantage and provides information about the colour vision function which is a subjective test and in our study group students being from medical college cooperation from the subjects does not require any special skill or preparation. For students who are unable to understand the test at all, explaining them the physiological aspects of the test made them easy undergo the tests. The main difficulty is to make the subjects able to tell what exactly they are seeing in the Ishihara charts.

In this study we have subjected one thousand students who routinely undergo vision screening tests at the time of admission into medical college for visual acuity and colour vision by Snellen and Ishihara charts.Testing is done by using special images called pseudoisochromatic plates. These images are made of colored dots that have numbers or symbols embedded within them. Only people with normal vision can see these numbers and symbols. If color blind, subject may not see the number or may see a different number. We made students to understand the test and tell what exactly they see. If the student is wearing glasses or contact lenses ,he should continue to wear them during the exam.This test has no associated risks, and no special preparation is necessary.

Inclusion criteria: Medical students of Shadan Institute of Medical Sciences, after taking written informed consent.

Exclusion criteria: Students diagnosed with eye diseases such as squint or cataracts were excluded from the study.

\section{Results}

Of the 1000 participated in the color vision screening, 572 (57.2\%) males and 428 (42.8\%) females, aged 18 to 21 years. Of these, 78 students were having abnormal color vision with red-green CVD that could not be classified by the two color tests. All 78 students with suspected color vision defects by first test are examined for the second time after sometime and confirmed to avoid false positives.Out of 1000 students subjected to the tests,78 colour vision defect cases were identified and all of them are males and have red - green type of colour vision defect which is significant number and correlation with blood group shows almost equal prevalence in ' $\mathrm{O}$ ' \& ' $\mathrm{B}$ ' +ve blood groups as $35 \%$ and $33 \%$ respectively, followed by 'A' $22 \%$ and 'AB' $8 \%$.None of the female students detected with colour vision defect. Out of 572 males and 428 females 52 males and 44 females are having myopia respectively and none of them have colour vision defects 
Table 1. Different blood group types in the study group and visual acuity findings.

\begin{tabular}{|c|c|c|c|c|c|c|c|c|c|c|c|c|c|c|}
\hline \multirow{4}{*}{$\begin{array}{l}\begin{array}{l}\text { Total No.of } \\
\text { Subjects }\end{array} \\
1000\end{array}$} & \multirow{4}{*}{$\begin{array}{l}\text { Gender } \\
\mathrm{M} / \mathrm{F}\end{array}$} & \multicolumn{8}{|c|}{ Type of Blood Group } & \multirow{2}{*}{\multicolumn{3}{|c|}{ Visual acuity }} & \multirow{2}{*}{\multicolumn{2}{|c|}{$\begin{array}{l}\text { Type of color } \\
\text { vision defect }\end{array}$}} \\
\hline & & \multicolumn{2}{|l|}{ A } & \multicolumn{2}{|l|}{ B } & \multicolumn{2}{|c|}{$\mathbf{A B}$} & \multicolumn{2}{|l|}{$\mathbf{O}$} & & & & & \\
\hline & & \multirow{2}{*}{$\begin{array}{l}\mathrm{Rh} \\
+\mathrm{ve}\end{array}$} & \multirow{2}{*}{$\begin{array}{l}\mathrm{Rh} \\
-\mathrm{ve}\end{array}$} & \multirow{2}{*}{$\begin{array}{l}\mathrm{Rh} \\
+\mathrm{ve}\end{array}$} & \multirow{2}{*}{$\begin{array}{l}\text { Rh } \\
\text {-ve }\end{array}$} & \multirow{2}{*}{$\begin{array}{l}\mathrm{Rh} \\
+\mathrm{ve}\end{array}$} & \multirow{2}{*}{$\begin{array}{l}\text { Rh } \\
\text {-ve }\end{array}$} & \multirow{2}{*}{$\begin{array}{l}\mathrm{Rh} \\
+\mathrm{ve}\end{array}$} & \multirow{2}{*}{$\begin{array}{l}\mathrm{Rh} \\
-\mathrm{ve}\end{array}$} & \multirow{2}{*}{ Normal } & \multicolumn{2}{|c|}{ Myopia } & \multirow{2}{*}{$\begin{array}{l}\text { Red- } \\
\text { Green }\end{array}$} & \multirow{2}{*}{ Others } \\
\hline & & & & & & & & & & & $\begin{array}{l}< \\
4\end{array}$ & $>4$ & & \\
\hline Male & 572 & 118 & 10 & 214 & 04 & 48 & 0 & 164 & 14 & 520 & 38 & 14 & 78 & ----- \\
\hline Female & 428 & 89 & 08 & 138 & 04 & 34 & 0 & 134 & 21 & 384 & 34 & 10 & nil & nil \\
\hline
\end{tabular}

Table 2. Percentage Distribution of Blood Groups among subjects with normal and deficient colour vision

\begin{tabular}{|c|c|c|c|c|c|c|c|c|}
\hline \multirow{3}{*}{$\begin{array}{l}\text { Blood group } \\
\text { type }\end{array}$} & \multicolumn{4}{|c|}{ Normal Subjects } & \multicolumn{4}{|c|}{ Subjects with colour vision defects } \\
\hline & \multicolumn{2}{|c|}{ Number } & \multicolumn{2}{|c|}{ Percentage $\%$} & \multicolumn{2}{|c|}{ Number } & \multicolumn{2}{|c|}{ Percentage \% } \\
\hline & Male & Female & Male & Female & Male & Female & Male & Female \\
\hline A & 128 & 97 & 22 & 23 & 25 & - & 32 & - \\
\hline B & 218 & 142 & 38 & 33 & 21 & - & 27 & - \\
\hline $\mathrm{AB}$ & 48 & 35 & 8 & 8 & 8 & - & 10 & - \\
\hline $\mathrm{O}$ & 178 & 154 & 32 & 36 & 24 & - & 31 & - \\
\hline Total & 572 & 428 & 100 & 100 & 78 & & 100 & \\
\hline
\end{tabular}

\section{Discussion}

OPN1LW produces red-sensitive opsin, OPN1MW and OPN1SW, produce green-sensitive and blue-sensitive opsin respectively ${ }^{[10]}$. OPN1LW and OPN1MW are on the $\mathrm{X}$ chromosome at position Xq28 ${ }^{[1]}$. Genetic changes of the OPN1LW and/or OPN1MW genes can cause red-green colourblindness ${ }^{[12]}$. These genetic changes involve recombination events between the highly similar genes of OPN1LW and OPN1MW, which can result in deletion of one or both of these genes $^{[13]}$.

Protanopia is caused by defective or total loss of the OPN1LW gene function, causing vision that is entirely dependent on OPN1MW and OPN1SW ${ }^{[14]}$. Affected individuals have dichromatic vision, with the inability to fully differentiate between green, yellow, and red colour.

During eye development, early visual experience plays a critical role in controlling eye growth, with a predictable change in axial length to match the position of the image focal plane with the retinal plane ${ }^{[14]}$. Shifting the image focal plane to a position in front of or behind the retina, leads to a shorter or longer axial length and consequently a hyperopic or myopic eye ${ }^{[15]}$. The process by which the eye grows to match its retina with the image focal plane is called emmetropization, responsible for elimination of refractive errors in neonates during early eye development. The optical system is not free of 
chromatic aberration. Longitudinal chromatic aberration (LCA), caused by the dispersion of the ocular media, causes a single object to form multiple chromatic images within the eye, located at different distances from the retina for different color images. A distant object could produce a red (long-wavelength [L]) image behind the retina, a blue (short-wavelength [S]) image in front of the retina, and green and yellow (middle-wavelength [M]) images near or at the retina. In the human eye, the long-wavelength $(700 \mathrm{~nm})$ and short-wavelength (450 $\mathrm{nm}$ ) images are separated by approximately 1.7 to $2.0 \mathrm{D}$, with very small individual variations ${ }^{[16]}$.

As Blood group types and CVDs are inherited as genetic traits from parents, several studies are conducted to find the influence of blood type on CVDs. For CVD and blood type phenotype -genotype correspondence reflects a shared genetic influence. No significant differences in the distribution of both these genetic traits is found. No significant correlation in blood type and CVDs are evident. Some studies have shown prevalence of CVDs in males with blood type "B+Ve".

\section{Conclusion}

Screening test for congenital colour vision deficiencies should be made mandatory for children as there is injury risk. Experimental study by Reiss and colleagues suggested that CVDs impaired recognition of blood in body fluids may contribute to missing certain diseases like haematuria ,as recognition of blood may contribute to seeking prompt medical consultations and accelerate the diagnosis.

People who are colorblind often consciously apply certain techniques or use specific tools to make life easier. For example, memorizing the order of the lights from top to bottom on a traffic light removes the need to distinguish its colors.Labeling clothing can assist in matching colors properly. Some software applications (apps developed by CVD patients themselves) transform computer colors into those that colorblind people can see. Inherited color blindness is a lifelong challenge. While it may limit prospects for certain jobs, such as working as an electrician who must tell the difference between color-coded wires, most people find ways to adapt to the condition. With the use of software and /or glasses that may help in identifying colours early diagnosis will help to improve vision, if not in total as there is no cure for colour blindness and help them cope with the defect by applying certain techniques or use specific tools to make life easier and safe.

Ethical Clearance: Instituitional ethical committee permission was taken.

\section{Source of Funding: Self}

\section{Conflict of Interest: None}

\section{References}

1. D M Hunt, K S Dulai, J K Bowmaker, J D Mollon. et al. The chemistry of John Dalton's color blindness; 1995, doi:10.1126/science.267(5200)984-8.

2. Smith VC, Pokorny J. Spectral sensitivity of the foveal cone photopigments between 400 and 500 nm. Vision Res;1975, 15:161- 171.

3. Derrington AM, Krauskopf J, Lennie P. et al.Chromatic mechanisms in lateral geniculate nucleus of macaque. J Physiol, 1984, 357:241265.

4. Pokorny J, Moreland JD, Smith VC. et al. Photopigments in anomalous trichromats. J Opt Soc Am, 1975, 65:1522-1524.

5. Alpern M, Moeller J. The red and green cone visual pigments of deuteranomalous trichromacy. $\mathrm{J}$ Physiol.1977, 266:647-675.

6. He JC, Shevell SK. Variation in color matching and discrimination among deuteranomalous trichromats: theoretical implications of small differences in photopigments. Vision Res. 1995,n35:2579- 2588.

7. Smith VC, Pokorny J. Color matching and discrimination. In: Shevell SK, ed. The Science of Color. 2nd ed. Oxford, UK: Elsevier. 2003:103148.

8. DeMarco P, Pokorny J, Smith VC. et al. Full-spectrum cone sensitivity functions for X-chromosome-linked anomalous trichromats. J Opt Soc Am A.9: 1992, 1465-1472.

9. Rucker FJ, Kruger PB. Cone contributions to signals for accommodation and the relationship to refractive error. Vision Res; 2006,46:3079-3089.

10. Hofmann 1, Palczewski K. "Advances in understanding the molecular basis of the first steps 
in colour vision". Progress in Retinal and Eye Research. 2015,49:46-66.

11. Merbs SL, Nathans J. "Absorption spectra of human cone pigments".Nature.1992, (6368):433-5.

12. Neitz J, Neitz M. "The genetics of normal amd defective color vision".Vision Research. 2010,51(7)633-51.

13. Deeb SS "Genetics of variation in human colour vision and the retinal cone mosaic". Current Opinion in Genetics and Development. 2006 16(3): 301-7.
14. Wald G, Griffin DR. The change in refractive power of the human eye in dim and bright light. $\mathrm{J}$ Opt Soc Am; 1947, 37:321-336.

15. Bedford RE, Wyszecki G. Axial chromatic aberration of the human eye. J Opt Soc Am:1957,47:564-565.

16. Howarth PA, Bradley A. The longitudinal chromatic aberration of the human eye and its correction. Vision Res; 1986, 26:361-366. 